\title{
Pulmonary function tests do not predict mortality in patients undergoing continuous-flow left ventricular assist device implantation
}

\author{
Edo K. S. Bedzra, MD, MBA, ${ }^{\mathrm{a}}$ Todd F. Dardas, MD, MS, ${ }^{\mathrm{b}}$ Richard K. Cheng, MD, MS, ${ }^{\mathrm{b}}$ \\ Jay D. Pal, MD, PhD, ${ }^{a}$ Claudius Mahr, DO, ${ }^{\mathrm{b}}$ Jason W. Smith, MD, ${ }^{a}$ Kent Shively, BS, ${ }^{\mathrm{a}}$ \\ S. Carolina Masri, MD, ${ }^{b}$ Wayne C. Levy, MD, ${ }^{b}$ and Nahush A. Mokadam, MD
}

\section{ABSTRACT}

Objectives: To investigate the effect of pulmonary function testing on outcomes after continuous flow left ventricular assist device implantation.

Methods: A total of 263 and 239 patients, respectively, had tests of forced expiratory volume in 1 second and diffusing capacity of the lungs for carbon monoxide preoperatively for left ventricular assist device implantations between July 2005 and September 2015. Kaplan-Meier analysis and multivariable Cox regressions were performed to evaluate mortality. Patients were analyzed in a single cohort and across 5 groups. Postoperative intensive care unit and hospital lengths of stay were evaluated with negative binomial regressions.

Results: There is no association of forced expiratory volume in 1 second and diffusing capacity of the lungs for carbon monoxide with survival and no difference in mortality at 1 and 3 years between the groups $(\log$ rank $P=.841$ and .713 , respectively). Greater values in either parameter were associated with decreased hospital lengths of stay. Only diffusing capacity of the lungs for carbon monoxide was associated with increased intensive care unit length of stay in the group analysis $(P=.001)$. Ventilator times, postoperative pneumonia, reintubation, and tracheostomy rates were similar across the groups.

Conclusions: Forced expiratory volume in 1 second and diffusing capacity of the lungs for carbon monoxide are not associated with operative or long-term mortality in patients undergoing continuous flow left ventricular assist device implantation. These findings suggest that these abnormal pulmonary function tests alone should not preclude mechanical circulatory support candidacy. (J Thorac Cardiovasc Surg 2017;154:1959-70)

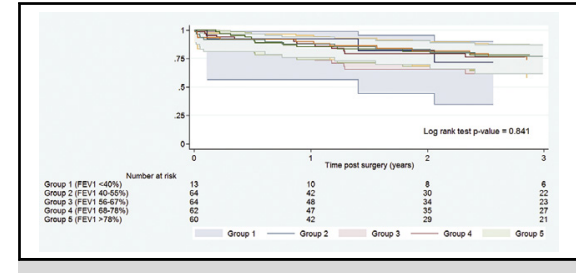

Kaplan-Meier survival estimates for patients by FEV group.

Central Message

Abnormal pulmonary function tests alone should not preclude mechanical circulatory support candidacy.

\section{Perspective}

Many centers consider abnormal pulmonary function tests a barrier to mechanical circulatory support candidacy, but there is little research on their prognostic implications. In this retrospective series, there is no association of abnormal tests with increased mortality after left ventricular assist device implantation. Pulmonary function tests alone should not preclude mechanical circulatory support.

See Editorial Commentary page 1971.

See Editorial page 1957.
The prevalence of heart failure is increasing steadily in the United States. ${ }^{1}$ Mechanical circulatory support (MCS) is a proven therapy in advanced heart failure and is shown to improve survival in selected patients. ${ }^{2}$ The presence of

\footnotetext{
From the Divisions of ${ }^{\mathrm{a}}$ Cardiothoracic Surgery and ${ }^{\mathrm{b}}$ Cardiology, University of Washington Medical Center, Seattle, Wash.

Read at the 42nd Annual Meeting of The Western Thoracic Surgical Association, Waikoloa, Hawaii, June 22-25, 2016.

Received for publication June 8, 2016; revisions received Jan 10, 2017; accepted for publication Feb 12, 2017; available ahead of print May 16, 2017.

Address for reprints: Edo K. S. Bedzra, MD, MBA, 1959 NE Pacific St, Box 356310, Seattle, WA 98195 (E-mail: ebedzra@uw.edu).

$0022-5223 / \$ 36.00$

Copyright (C) 2017 by The American Association for Thoracic Surgery http://dx.doi.org/10.1016/j.jtcvs.2017.02.069
}

lung disease is associated with increased mortality in the Society of Thoracic Surgeons risk calculator. ${ }^{3}$ However, in heart failure surgery, studies of pulmonary function tests (PFTs) have found both a negative correlation with mortality and postoperative pulmonary complications as well as an absence of any relationship between the tests and outcomes. ${ }^{4-12}$ This may be distinct from noncardiac

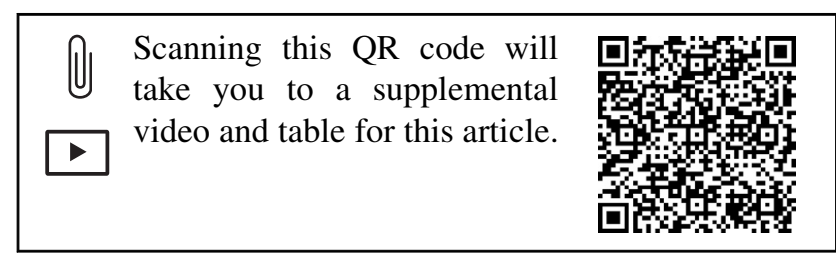




\begin{tabular}{|c|c|}
\hline \\
\hline \multicolumn{2}{|c|}{$\mathrm{CI}=$ confidence interval } \\
\hline DLCO & $\begin{array}{l}=\text { diffusion capacity of the lungs for } \\
\text { carbon monoxide }\end{array}$ \\
\hline $\mathrm{FEV}_{1}$ & $\begin{aligned}= & \text { forced expiratory volume in } \\
& 1 \text { second }\end{aligned}$ \\
\hline ICU & $=$ intensive care unit \\
\hline INTER & $=$ Interagency Registry For \\
\hline & $\begin{array}{l}\text { Mechanically Assisted Circulatory } \\
\text { Support }\end{array}$ \\
\hline LOS & $=$ length of stay \\
\hline LVAD & $=$ left ventricular assist device \\
\hline MCS & $=$ mechanical circulatory support \\
\hline PFT & $=$ pulmonary function test \\
\hline
\end{tabular}

thoracic surgery, in which preoperative pulmonary function measures are correlated unequivocally with postoperative morbidity and mortality. ${ }^{13}$ Many heart failure centers evaluate PFTs when considering patients for MCS.

This study investigates the efficacy of percent predicted forced expiratory volume in 1 second $\left(\mathrm{FEV}_{1}\right)$ and diffusion capacity of the lungs for carbon monoxide (DLCO) in predicting mortality in patients with heart failure who undergo implantation of a continuous-flow left ventricular assist device (LVAD). Secondary measures such as intensive care unit (ICU) and total hospital lengths of stay (LOS) are also explored.

\section{METHODS}

\section{Patients and Methods}

Institutional review board approval was obtained to retrospectively review the MCS quality improvement database at a single institution. A total of 310 sequential patients who underwent continuous-flow LVAD implantations for all indications between July 2005 and September 2015 were evaluated. All patients with recorded data for $\mathrm{FEV}_{1}$ and DLCO were included in our primary analysis. All patients with DLCO testing also had $\mathrm{FEV}_{1}$ testing, but the reverse was not true. Patients with no PFT testing were excluded from initial analyses, leaving 263 (85\%) and $239(77 \%)$ patients, respectively, for further analysis. Patients were then stratified into groups based on the respective PFTs. A cutoff value of $40 \%$ was chosen for the first group, which is a more stringent criterion for pulmonary dysfunction than previously used in the literature. ${ }^{3,4,10}$ The remaining patients were then stratified accounting for even distribution of patients to allow statistical comparison. For $\mathrm{FEV}_{1}$, the groups were defined as follows: Group 1: $\mathrm{FEV}_{1}<40 \%$ predicted, Group 2: $\mathrm{FEV}_{1} 40 \%$ to $55 \%$ predicted, Group 3: $\mathrm{FEV}_{1} 56 \%$ to $67 \%$ predicted, Group 4: $\mathrm{FEV}_{1} 68 \%$ to $78 \%$ predicted, and Group $5: \mathrm{FEV}_{1}>78 \%$ predicted. DLCO groups were defined as Group 1: DLCO $<40 \%$ predicted, Group 2: DLCO $40 \%$ to $46 \%$ predicted, Group 3: DLCO $47 \%$ to $53 \%$ predicted, Group 4 : DLCO $54 \%$ to $61 \%$ predicted, and Group 5: DLCO $>61 \%$ predicted.

Demographic, preoperative, operative, and postoperative variables such as serum creatinine, hemodynamic profile and Interagency Registry For Mechanically Assisted Circulatory Support (INTERMACS) profile, cardiopulmonary bypass time, reoperation status, additional cardiac surgical procedures at the time of implantation, ventilator time, postoperative pneumonia, reintubation status, tracheostomy, postoperative ICU and total hospital LOS, and mortality at 30 days, 1 year, and 3 years were collected.

\section{Statistical Analysis}

Univariate and multivariable analyses were performed on outcome variables, with adjustment for factors such as age, sex, INTERMACS profile, serum creatinine, reoperation status, ventilator time, postoperative pneumonia, and cardiopulmonary bypass time, which are known risk factors for poor outcomes after cardiac surgery. First, the data were analyzed with $\mathrm{FEV}_{1}$ and DLCO treated as continuous variables. Comparisons were then made across groups using the group with highest observed values as a reference.

Overall survival analysis was conducted with the Kaplan-Meier method. Multivariable regressions were performed with the Cox proportional hazard model, which was applied to the entire cohort with the categories of $\mathrm{FEV}_{1}$ and DLCO entered into the model. The proportional-hazard assumption was tested, on basis of Schoenfeld residuals from separate Cox proportional hazard models, treating the variables as continuous and then as categorical and was not violated $\left(P=\mathrm{FEV}_{1}\right.$ and DLCO .413 and .152 , and .222 and .090 , respectively, for continuous and categorical variables). LOS analysis was performed with negative binomial regressions to accommodate overdispersion of this outcome variable. For time-to-event analyses, patients were followed from implant until death without censoring for LVAD exchange, explant, or heart transplantation. Sensitivity analyses were performed by including patients with no PFT data in the lowest groups. Furthermore, $\mathrm{FEV}_{1}$ and DLCO were included as linear splines to detect possible nonlinear relationship which was absent (Table E1). All statistical analyses were performed with Stata, version 14 (Stata Corporation, College Station, Tex).

\section{RESULTS}

\section{Baseline Characteristics}

The baseline characteristics are reported in Table 1. The average patient presented for implantation as INTERMACS 3. The average age of patients in the $\mathrm{FEV}_{1}$ cohort was 54 years; $81.7 \%$ were male, and $60.5 \%$ of these patients were eligible for transplantation, three quarters of whom underwent eventual heart transplantation. The average time from LVAD implantation to heart transplantation was 282 days. There was no difference in rates of heart transplantation across any of the $5 \mathrm{FEV}_{1}$ or DLCO groups (average $45.6 \%, P=.56$, and $45.2 \%, P=.99$, respectively). $\mathrm{FEV}_{1}$ ranged from $23 \%$ to $113 \%$ predicted, whereas DLCO ranged from $28 \%$ to $101 \%$ predicted. Heartmate II (St Jude, St. Paul, Minn) implantations comprised $79 \%$ of procedures in the $\mathrm{FEV}_{1}$ group, whereas the remainder underwent HeartWare HVAD (HeartWare, Framingham, Mass) implantation. There was a similar distribution for the DLCO analysis.

\section{Hemodynamic Profile}

The average patient had a left ventricular ejection fraction of $19.7 \%$, a cardiac index of $2.3 \mathrm{~L} / \mathrm{min} / \mathrm{m}^{2}$, and a mean pulmonary arterial pressure of $32 \mathrm{~mm} \mathrm{Hg}$ with a pulmonary capillary wedge pressure of $22 \mathrm{~mm} \mathrm{Hg}$. A total of $17.3 \%$ were supported with intra-aortic balloon pumps (Table 2). The average serum creatinine level was $1.3 \mathrm{mg} / \mathrm{dL}$. On group level analysis, the only significant difference between groups was found in the INTERMACS profile at presentation (2.3, standard deviation [SD], 0.5, in the lowest $\mathrm{FEV}_{1}$ group vs 3.1 [SD 1.0] in the highest group, $P=.01$ ). In the DLCO groups, a greater percentage of patients with lower test values 
TABLE 1. Demographics and baseline characteristics

\begin{tabular}{|c|c|c|c|c|c|c|c|}
\hline Characteristic & 1 & 2 & 3 & 4 & 5 & Total & $P$ value \\
\hline \multicolumn{8}{|l|}{$\mathrm{FEV}_{1}$ group } \\
\hline $\mathrm{n}$ & 13 & 57 & 64 & 67 & 62 & 263 & \\
\hline Age, mean (SD) & $49.4(14.2)$ & $54.9(13.8)$ & $55.2(12.1)$ & $55.8(13.5)$ & $51.9(14.3)$ & $54.2(13.5)$ & .3 \\
\hline Sex, male & $10(77 \%)$ & $46(81 \%)$ & $57(89 \%)$ & $55(82 \%)$ & $47(76 \%)$ & $215(81.7 \%)$ & .4 \\
\hline $\begin{array}{l}\text { INTERMACS profile, mean } \\
\text { (SD) }\end{array}$ & $2.3(0.5)$ & $2.9(1.2)$ & $3.0(1.1)$ & $3.4(1.3)$ & $3.1(1.0)$ & $3.1(1.2)$ & .0124 \\
\hline \multicolumn{8}{|l|}{ Device } \\
\hline HeartWare & $3(23 \%)$ & $10(18 \%)$ & $14(22 \%)$ & $12(18 \%)$ & $16(26 \%)$ & $55(20.9 \%)$ & .79 \\
\hline HeartMate II & $10(77 \%)$ & $47(82 \%)$ & $50(78 \%)$ & $55(82 \%)$ & $46(74 \%)$ & $208(79.1 \%)$ & \\
\hline \multicolumn{8}{|l|}{ Intent of therapy } \\
\hline Bridge to transplantation & $1(8 \%)$ & $21(33 \%)$ & $32(50 \%)$ & $33(53 \%)$ & $32(53 \%)$ & $119(45.2 \%)$ & .024 \\
\hline Bridge to eligibility & $5(38 \%)$ & $11(17 \%)$ & $11(17 \%)$ & $7(11 \%)$ & $8(13 \%)$ & $42(16.0 \%)$ & \\
\hline Destination therapy & $7(54 \%)$ & $32(50 \%)$ & $21(33 \%)$ & $22(35 \%)$ & $20(33 \%)$ & $102(38.8 \%)$ & \\
\hline \multicolumn{8}{|l|}{ DLCO group } \\
\hline $\mathrm{n}$ & 41 & 55 & 51 & 46 & 46 & 239 & \\
\hline Age, mean (SD) & $56.6(14.0)$ & $54.7(13.5)$ & $54.8(11.2)$ & $54.6(13.9)$ & $51.3(14.4)$ & $54.4(13.4)$ & .45 \\
\hline Sex, male & $38(93 \%)$ & $46(84 \%)$ & $41(80 \%)$ & $37(80 \%)$ & $34(74 \%)$ & $196(82.0 \%)$ & .24 \\
\hline $\begin{array}{l}\text { INTERMACS profile, mean } \\
\text { (SD) }\end{array}$ & $2.9(1.3)$ & $2.9(1.1)$ & $3.2(1.1)$ & $3.2(1.3)$ & $3.1(1.0)$ & $3.1(1.2)$ & .57 \\
\hline \multicolumn{8}{|l|}{ Device } \\
\hline Heartware & $8(20 \%)$ & $7(13 \%)$ & $9(18 \%)$ & $11(24 \%)$ & $10(22 \%)$ & $45(18.8 \%)$ & .66 \\
\hline Heartmate II & $33(80 \%)$ & $48(87 \%)$ & $42(82 \%)$ & $35(76 \%)$ & $36(78 \%)$ & $194(81.2 \%)$ & \\
\hline \multicolumn{8}{|l|}{ Intent of therapy } \\
\hline Bridge to transplantation & $12(29 \%)$ & $26(47 \%)$ & $20(39 \%)$ & $20(43 \%)$ & $24(52 \%)$ & $119(45.2 \%)$ & .38 \\
\hline Bridge to eligibility & $6(15 \%)$ & $6(11 \%)$ & $11(22 \%)$ & $9(20 \%)$ & $6(13 \%)$ & $42(16.0 \%)$ & \\
\hline Destination therapy & $23(56 \%)$ & $23(42 \%)$ & $20(39 \%)$ & $17(37 \%)$ & $16(35 \%)$ & $102(38.8 \%)$ & \\
\hline
\end{tabular}

$\mathrm{FEV}_{l}$, Forced expiratory volume in 1 second; SD, standard deviation; INTERMACS, Interagency Registry For Mechanically Assisted Circulatory Support; DLCO, diffusion capacity of the lungs for carbon monoxide.

were supported with an intra-aortic balloon pump at implantation $(34 \%$ in the lowest DLCO group vs $7 \%$ in the highest DLCO group, $P$ value .01 ), and right-sided fill pressures tended to be greater $(12.2 \mathrm{~mm} \mathrm{Hg}$ [SD 5.3] in the lowest $\mathrm{FEV}_{1}$ group vs 7.8 [SD 4.8] $\mathrm{mm} \mathrm{Hg}$ in the highest $\mathrm{FEV}_{1}$ group, $P<.001$ for right atrial pressures), where as the trend was towards a greater wedge pressure in groups with lower $\mathrm{FEV}_{1}\left(24.3 \mathrm{~mm} \mathrm{Hg}\right.$ in the lowest $\mathrm{FEV}_{1}$ group vs $20.3 \mathrm{~mm} \mathrm{Hg}$ in the highest $\mathrm{FEV}_{1}$ group, $P=$ .057). All other measures were similar across the groups.

\section{Intraoperative Details}

A total of $19.8 \%$ of patients had undergone a previous sternotomy for cardiac surgery before LVAD implantation (Table 3). A total of $31.2 \%$ of patients had additional procedures at the time of surgery, including tricuspid valve repair $(25.1 \%)$ and aortic valve repair. A total of $2.7 \%$ of patients required implantation of a right ventricular assist device at the time of surgery. The average cardiopulmonary bypass time was 90.8 minutes.

\section{Postoperative Outcomes}

Postoperative outcomes for the patient population are listed in Tables 3 and 4 (additional data are available in Table E1). The average ventilator time was 51.1 hours for the $\mathrm{FEV}_{1}$ cohort with a median of 24 hours (interquartile range, 19-43), reflecting the outliers with very prolonged ventilator times (maximum 1222 hours). Reintubation, postoperative pneumonia, and tracheostomy rates were $10.6 \%, 6.8 \%$, and $3.8 \%$, respectively. There were no significant differences in these pulmonary function measures across the $5 \mathrm{FEV}_{1}$ groups $(P=.54, .12, .36$, and .61 for ventilator time, postoperative pneumonia, reintubation, and tracheostomy rates).

The median ventilator time was 25 hours (interquartile range 20-43) for the DLCO cohort. Reintubation, postoperative pneumonia, and tracheostomy rates were $9.6 \%, 6.7 \%$, and $3.3 \%$, respectively. There were no significant differences in these pulmonary function measures across the 5 DLCO groups $(P=.24, .09, .29$, and .07 for ventilator time, postoperative pneumonia, reintubation, and tracheostomy rates, respectively).

In the linear analysis, there was no association of $\mathrm{FEV}_{1}$ or DLCO with survival (hazard ratio 0.99 , confidence interval [CI] 0.84-1.18 and 0.91, CI 0.73-1.14; $P=.925$ and .435 , respectively). This relationship held after adjustments in a multivariable model. However, there was a negative correlation between these PFT parameters and hospital LOS. Each $10 \%$-point increase in $\mathrm{FEV}_{1}$ or DLCO was associated with a 7\% decrease in hospital LOS (Table 4). 
TABLE 2. Hemodynamic profile and laboratory values

\begin{tabular}{|c|c|c|c|c|c|c|c|}
\hline Characteristic & 1 & 2 & 3 & 4 & 5 & Total & $P$ value \\
\hline \multicolumn{8}{|l|}{$\mathrm{FEV}_{1}$ group } \\
\hline $\mathrm{n}$ & 13 & 57 & 64 & 67 & 62 & 263 & \\
\hline Creatinine, $\mathrm{mg} / \mathrm{dL}$ & $1.3(0.4)$ & $1.3(0.4)$ & $1.4(0.4)$ & $1.2(0.4)$ & $1.2(0.4)$ & $1.3(0.4)$ & .14 \\
\hline $\begin{array}{l}\text { Intra-aortic balloon pump, } \\
\mathrm{n}(\%)\end{array}$ & $6(55)$ & $17(31)$ & $8(14)$ & $7(11)$ & $5(8)$ & $43(17.3)$ & $<.001$ \\
\hline $\begin{array}{l}\text { Right atrial pressure, } \mathrm{mm} \\
\mathrm{Hg}\end{array}$ & $12.2(5.3)$ & $11.3(5.3)$ & $11.6(6.7)$ & $8.6(4.2)$ & $7.8(4.8)$ & $9.9(5.5)$ & $<.001$ \\
\hline $\begin{array}{l}\text { Right ventricular systolic } \\
\text { pressure, } \mathrm{mm} \mathrm{Hg}\end{array}$ & $49.5(9.6)$ & $47.9(12.0)$ & $49.7(13.2)$ & $46.9(14.5)$ & $44.1(15.9)$ & $47.3(13.9)$ & .25 \\
\hline $\begin{array}{l}\text { Right ventricular diastolic } \\
\text { pressure, } \mathrm{mm} \mathrm{Hg}\end{array}$ & $13.3(5.2)$ & $11.6(5.6)$ & $11.2(6.3)$ & $9.3(5.6)$ & $8.7(5.4)$ & $10.3(5.8)$ & .01 \\
\hline $\begin{array}{l}\text { Mean pulmonary arterial } \\
\text { pressure, } \mathrm{mm} \mathrm{Hg}\end{array}$ & $36.4(6.4)$ & $33.1(7.3)$ & $34.0(8.4)$ & $30.8(9.8)$ & $29.9(10.0)$ & $32.1(9.0)$ & .03 \\
\hline $\begin{array}{l}\text { Pulmonary capillary wedge } \\
\text { pressure, } \mathrm{mm} \mathrm{Hg}\end{array}$ & $24.3(5.8)$ & $24.1(7.4)$ & $22.7(7.2)$ & $21.7(8.8)$ & $20.0(7.9)$ & $22.2(7.9)$ & .06 \\
\hline $\begin{array}{l}\text { Cardiac output by } \\
\text { thermodilution, } \mathrm{L} / \mathrm{min}\end{array}$ & $4.5(1.0)$ & $4.7(1.3)$ & $5.1(3.1)$ & $4.6(1.4)$ & $4.5(1.2)$ & $4.7(1.9)$ & .48 \\
\hline $\begin{array}{l}\text { Cardiac index by } \\
\text { thermodilution, } \mathrm{L} / \mathrm{min} / \\
\mathrm{m}^{2}\end{array}$ & $2.4(0.4)$ & $2.2(0.6)$ & $2.3(0.7)$ & $2.3(0.7)$ & $2.3(0.6)$ & $2.3(0.6)$ & .94 \\
\hline $\begin{array}{l}\text { Left ventricular ejection } \\
\text { fraction, } \%\end{array}$ & $18.9(9.4)$ & $19.0(7.3)$ & $19.9(7.1)$ & $19.5(6.3)$ & $20.6(6.3)$ & $19.7(6.9)$ & .74 \\
\hline \multicolumn{8}{|l|}{ DLCO group } \\
\hline $\mathrm{n}$ & 41 & 55 & 51 & 46 & 46 & 239 & \\
\hline Creatinine, $\mathrm{mg} / \mathrm{dL}$ & $1.3(0.4)$ & $1.4(0.5)$ & $1.3(0.4)$ & $1.2(0.3)$ & $1.3(0.4)$ & $1.3(0.4)$ & .12 \\
\hline $\begin{array}{l}\text { Intra-aortic balloon pump, } \\
\mathrm{n}(\%)\end{array}$ & $13(34)$ & $11(20)$ & $8(17)$ & $5(11)$ & $3(7)$ & $40(17.5)$ & .01 \\
\hline $\begin{array}{l}\text { Right atrial pressure, } \mathrm{mm} \\
\mathrm{Hg}\end{array}$ & $9.3(6.0)$ & $10.3(5.1)$ & $10.9(6.3)$ & $9.4(5.2)$ & $10.0(5.1)$ & $10.0(5.5)$ & .67 \\
\hline $\begin{array}{l}\text { Right ventricular systolic } \\
\text { pressure, } \mathrm{mm} \mathrm{Hg}\end{array}$ & $46.9(12.5)$ & $47.8(14.4)$ & $50.3(13.4)$ & $46.4(14.8)$ & $46.6(13.7)$ & $47.6(13.8)$ & .65 \\
\hline $\begin{array}{l}\text { Right ventricular diastolic } \\
\text { pressure, } \mathrm{mm} \mathrm{Hg}\end{array}$ & $9.9(6.2)$ & $10.5(5.4)$ & $10.3(5.7)$ & $10.5(5.9)$ & $10.8(6.1)$ & $10.4(5.8)$ & .97 \\
\hline $\begin{array}{l}\text { Mean pulmonary arterial } \\
\text { pressure, } \mathrm{mm} \mathrm{Hg}\end{array}$ & $31.5(8.2)$ & $32.7(9.2)$ & $33.4(8.2)$ & $31.5(10.3)$ & $32.0(8.3)$ & $32.3(8.9)$ & .83 \\
\hline $\begin{array}{l}\text { Pulmonary capillary wedge } \\
\text { pressure, } \mathrm{mm} \mathrm{Hg}\end{array}$ & $21.1(8.2)$ & $22.5(7.0)$ & $22.7(8.0)$ & $22.2(9.0)$ & $23.5(7.0)$ & $22.4(7.8)$ & .71 \\
\hline $\begin{array}{l}\text { Cardiac output by } \\
\text { thermodilution, } \mathrm{L} / \mathrm{min}\end{array}$ & $4.8(1.3)$ & $5.0(3.2)$ & $4.7(1.1)$ & $4.5(1.4)$ & $4.8(1.5)$ & 4.8 (1.9) & .75 \\
\hline $\begin{array}{l}\text { Cardiac index by } \\
\text { thermodilution, } \mathrm{L} / \mathrm{min} / \\
\mathrm{m}^{2}\end{array}$ & $2.4(0.6)$ & $2.3(0.7)$ & $2.3(0.6)$ & $2.2(0.6)$ & $2.3(0.7)$ & $2.3(0.6)$ & .52 \\
\hline $\begin{array}{l}\text { Left ventricular ejection } \\
\text { fraction, } \%\end{array}$ & $21.3(8.5)$ & $19.7(7.8)$ & $19.1(6.8)$ & $19.0(5.3)$ & $20.7(6.1)$ & $19.9(7.0)$ & .48 \\
\hline
\end{tabular}

$F E V_{l}$, Forced expiratory volume in 1 second; $D L C O$, diffusion capacity of the lungs for carbon monoxide.

No linear effect was shown for ICU LOS, although analysis of the groups showed a correlation of increased ICU LOS with decreased DLCO for values greater than $46 \%$ predicted.

In the multivariable regression, age $>60$ years, postoperative pneumonia, and increasing cardiopulmonary bypass and ventilator times were associated with increasing risks of mortality. Female patients with postoperative pneumonia and longer ventilator times experienced longer ICU and hospital LOS.

\section{FEV $_{1}$ as Predictor of Outcomes}

Patients with $\mathrm{FEV}_{1}$ less than $40 \%$ predicted $(\mathrm{n}=13)$ had no operative deaths in this study. Mortality and 95\% CIs at 1 and 3 years were 0.09 (0.01-0.60) and 0.11 (0.04-0.34) deaths per person year, respectively. This did not differ significantly from patients with normal $\mathrm{FEV}_{1}$ values. In line with this, Kaplan-Meier analysis showed no difference in survival across groups (Figure 1, log rank $P=.841)$. Hospital LOS was significantly greater for patients with lower $\mathrm{FEV}_{1}$. Patients with $\mathrm{FEV}_{1}$ less 
TABLE 3. Perioperative details

\begin{tabular}{|c|c|c|c|c|c|c|c|}
\hline Characteristic & 1 & 2 & 3 & 4 & 5 & Total & $P$ value \\
\hline \multicolumn{8}{|l|}{$\mathrm{FEV}_{1}$ group } \\
\hline $\mathrm{n}$ & 13 & 57 & 64 & 67 & 62 & 263 & \\
\hline \multicolumn{8}{|l|}{ Intraoperative } \\
\hline Reoperation & $2(15 \%)$ & $12(21 \%)$ & $12(19 \%)$ & $20(30 \%)$ & $6(10 \%)$ & $52(19.8 \%)$ & .074 \\
\hline Tricuspid valve & $5(38 \%)$ & $16(28 \%)$ & $22(34 \%)$ & $11(16 \%)$ & $12(19 \%)$ & $66(25.1 \%)$ & .084 \\
\hline Aortic valve & $0(0 \%)$ & $2(4 \%)$ & $3(5 \%)$ & $2(3 \%)$ & $2(3 \%)$ & $9(3.4 \%)$ & .94 \\
\hline $\begin{array}{l}\text { Right ventricular assist } \\
\text { device }\end{array}$ & $1(8 \%)$ & $0(0 \%)$ & $1(2 \%)$ & $3(5 \%)$ & $2(3 \%)$ & $7(2.7 \%)$ & .4 \\
\hline $\begin{array}{l}\text { Cardiopulmonary bypass } \\
\text { time, mean }(\mathrm{SD})\end{array}$ & $110.5(42.3)$ & $94.3(34.7)$ & $94.3(41.4)$ & $86.6(52.6)$ & $84.5(44.6)$ & $90.8(44.2)$ & .27 \\
\hline \multicolumn{8}{|l|}{ Postoperative } \\
\hline $\begin{array}{l}\text { Ventilator time in hours, } \\
\text { median (IQR) }\end{array}$ & $24(17-51)$ & $25(20-45)$ & $24(19-40)$ & $24(22-41)$ & $23(17-38)$ & $24(19-43)$ & .47 \\
\hline Reintubation & $1(8 \%)$ & $6(9 \%)$ & $5(8 \%)$ & $11(18 \%)$ & $5(8 \%)$ & $28(10.6 \%)$ & .36 \\
\hline Pneumonia & $3(23 \%)$ & $3(5 \%)$ & $5(8 \%)$ & $2(3 \%)$ & $5(8 \%)$ & $18(6.8 \%)$ & .12 \\
\hline Tracheostomy & $0(0 \%)$ & $3(5 \%)$ & $2(3 \%)$ & $4(6 \%)$ & $1(2 \%)$ & $10(3.8 \%)$ & .61 \\
\hline \multicolumn{8}{|l|}{ DLCO group } \\
\hline $\mathrm{n}$ & 41 & 55 & 51 & 46 & 46 & 239 & \\
\hline \multicolumn{8}{|l|}{ Intraoperative } \\
\hline Reoperation & $15(37 \%)$ & $16(29 \%)$ & $7(14 \%)$ & $7(15 \%)$ & $5(11 \%)$ & $50(20.9 \%)$ & .009 \\
\hline Tricuspid valve & $11(27 \%)$ & $11(20 \%)$ & $14(27 \%)$ & $14(30 \%)$ & $14(30 \%)$ & $64(26.8 \%)$ & .75 \\
\hline Aortic valve & $1(2 \%)$ & $1(2 \%)$ & $1(2 \%)$ & $2(4 \%)$ & $4(9 \%)$ & $9(3.8 \%)$ & .36 \\
\hline $\begin{array}{l}\text { Right ventricular assist } \\
\text { device }\end{array}$ & $1(2 \%)$ & $1(2 \%)$ & $1(2 \%)$ & $0(0 \%)$ & $4(9 \%)$ & $7(3.0 \%)$ & .12 \\
\hline $\begin{array}{l}\text { Cardiopulmonary bypass } \\
\text { time, mean (SD) }\end{array}$ & $97.2(43.1)$ & $97.0(44.7)$ & $88.1(37.0)$ & $87.8(35.1)$ & $96.4(60.2)$ & $93.3(44.6)$ & .68 \\
\hline \multicolumn{8}{|l|}{ Postoperative } \\
\hline $\begin{array}{l}\text { Ventilator time in hours, } \\
\text { median (IQR) }\end{array}$ & $24(20-37)$ & $25(20-49)$ & $27(22-44)$ & $24(17-43)$ & $24(20-32)$ & $25(20-43)$ & .5 \\
\hline Reintubation & $3(7 \%)$ & $5(9 \%)$ & $5(10 \%)$ & $8(17 \%)$ & $2(4 \%)$ & $23(9.6 \%)$ & .29 \\
\hline Pneumonia & $3(7 \%)$ & $1(2 \%)$ & $3(6 \%)$ & $7(15 \%)$ & $2(4 \%)$ & $16(6.7 \%)$ & .094 \\
\hline Tracheostomy & $1(2 \%)$ & $0(0 \%)$ & $3(6 \%)$ & $4(9 \%)$ & $0(0 \%)$ & $8(3.3 \%)$ & .07 \\
\hline
\end{tabular}

$F E V_{l}$, Forced expiratory volume in 1 second; $S D$, standard deviation; $I Q R$, interquartile range; $D L C O$, diffusion capacity of the lungs for carbon monoxide.

than $40 \%$ predicted stayed 10 days longer in the hospital on average than patients with $\mathrm{FEV}_{1}$ greater than $78 \%$ predicted (ratio $1.43,95 \%$ CI 1.03-2.0, $P=.04$ ). Patients with $\mathrm{FEV}_{1} 68 \%$ to $78 \%$ predicted showed no significantly greater LOS than the normal group (Supplementary material). ICU LOS varied from 7.2 to 8.7 days in the different $\mathrm{FEV}_{1}$ groups, but no significant statistical difference existed between groups.

\section{DLCO as Predictor of Outcomes}

In the group of patients with DLCO less than $40 \%$ predicted $(\mathrm{n}=41)$, operative and medium term mortality rates and $95 \% \mathrm{CIs}$ at 1 and 3 years were $0,0.14$ (0.06-0.33), and $0.11(0.06-0.22)$ deaths per person-year. This was statistically similar to observed rates in the other groups and is reflected in the Kaplan-Meier analysis (Figure 2, $\log$ rank test $P$ value $=.713$ ). Hospital LOS was significantly longer in the groups with lower DLCO (Figure 3). Patients with DLCO less than 40\% predicted stayed 7 days longer on average than those with DLCO $>61 \%$ predicted (ratio 1.44 , 95\% CI 1.16-1.78,
$P<.001)$. However, patients with DLCO between $40 \%$ and $46 \%$ predicted $(\mathrm{n}=55)$ had no different LOS than patients with DLCO greater than $61 \%$ predicted $(n=40)$.

ICU LOS was significantly greater in Group 3, representing DLCO of $47 \%$ to $53 \%$ predicted compared with the group with DLCO $>61 \%$ predicted (ratio 1.78 , 95\% CI 1.3-2.4, $P<.001)$. However, patients with the lowest DLCO values in this study did not show increased ICU LOS compared with the reference group (Table E1).

\section{Sensitivity Analysis Results}

A total of 47 patients had no testing for $\mathrm{FEV}_{1}$, whereas 71 had none for DLCO. These patients were on average 4 years younger than patients who underwent testing $(P=.042)$, more likely to have worsening cardiac and renal function on inotropes (INTERMACS profile 2), and more likely to be supported with an intra-aortic balloon pump at implantation $(P$ value $<.001)$. In a Kaplan-Meier survival analysis, patients with no $\mathrm{FEV}_{1}$ testing had worse survival than the cohort of patients who were tested before implantation (log rank test $P=.046)$. When the former were included 
TABLE 4. Correlation of postoperative outcomes with pulmonary function tests as continuous variables

\begin{tabular}{|c|c|c|c|c|}
\hline \multirow[b]{2}{*}{ Outcome } & \multicolumn{2}{|l|}{$\mathbf{F E V}_{1}$} & \multicolumn{2}{|l|}{ DLCO } \\
\hline & Ratio & $P$ value & Ratio & $P$ value \\
\hline $\mathrm{N}$ & 263 & & 239 & \\
\hline \multicolumn{5}{|c|}{ Mortality (hazard ratio per $10 \%$ change)* } \\
\hline Unadjusted & $0.99(0.84-1.18)$ & .925 & $0.91(0.73-1.14)$ & .435 \\
\hline Adjusted & $1.08(0.90-1.30)$ & .433 & $0.98(0.77-1.24)$ & .838 \\
\hline \multicolumn{5}{|c|}{ Hospital length of stay (ratio of means per $10 \%$ change) $\dagger$} \\
\hline Unadjusted & $0.93(0.90-0.97)$ & .001 & $0.93(0.88-0.98)$ & .008 \\
\hline Adjusted & $0.94(0.91-0.98)$ & .002 & $0.93(0.88-0.97)$ & .004 \\
\hline \multicolumn{5}{|c|}{ ICU length of stay (ratio of means per $10 \%$ change) $\dagger$} \\
\hline Unadjusted & $1.00(0.94-1.06)$ & .936 & $0.96(0.88-1.04)$ & .286 \\
\hline Adjusted & $1.00(0.95-1.04)$ & .772 & $0.94(0.88-1.00)$ & .055 \\
\hline
\end{tabular}

Regressions adjusted for age, sex, INTERMACS profile, serum creatinine, reoperation status, ventilator time, postoperative pneumonia, and cardiopulmonary bypass time. $F E V_{l}$, Forced expiratory volume in 1 second; $D L C O$, diffusion capacity of the lungs for carbon monoxide; ICU, intensive care unit. *3-year mortality, Cox regression. $\dagger$ Negative binomial regression.

entirely in the lowest $\mathrm{FEV}_{1}$ group $\left(\mathrm{FEV}_{1}<40 \%\right.$ predicted), there were no observed changes in the relationships between groups. There was no observed difference in survival (ratio $1.68,95 \%$ CI $0.80-3.53, \log$ rank test $P=.462$ ) between the group inclusive of patients with no testing and the reference group $\left(\mathrm{FEV}_{1}>78 \%\right.$ predicted). The ratio of ICU LOS of patients with $\mathrm{FEV}_{1}$ less than $40 \%$ predicted to the reference increased from $1.08(.7-1.7)$ to 1.53 (1.11-2.11) with inclusion of patients with no $\mathrm{FEV}_{1}$ testing, but this remained statistically insignificant $(P=.062)$. Hospital LOS difference remained statistically significant (ratio $1.53,95 \%$ CI $1.22-1.92$ from 1.43 (1.0-2.0), $P=.03$ and $P<.001)$. Patients without DLCO testing had similar survival to the cohort of patients who were tested (log rank test, $P$ value .706).

\section{DISCUSSION}

Patient selection for advanced heart failure therapy, and more specifically, MCS, has been a focus of clinicians as devices have improved in reliability and durability. As a community, we generally have been successful in identifying patients who were ill enough to benefit from therapy. This has led to improved outcomes with 2-year survival in excess of $70 \%{ }^{14,15}$ However, our judgment has been challenged repeatedly in the assessment of those too ill to benefit from this therapy. This is because one of our major risk indicators, noncardiac frailty, cannot be expected to improve with improved hemodynamics, and the greater the noncardiac frailty, the less the potential benefit. ${ }^{16}$ Noncardiac frailty can take many forms, including physical debilitation, cachexia, and end-organ dysfunction. Although there are well-studied physical debilitation measures such as handgrip strength, gait speed, and unintentional weight loss, the prognostic value of end organ damage is still under investigation. There have been attempts at assessment of liver disease, which have suggested acceptable outcomes with liver dysfunction. ${ }^{17,18}$ Although continuous-flow LVAD implantation results in improved postoperative renal function, ${ }^{19}$ patients with preoperative renal dysfunction have been shown to have worse survival with MCS. ${ }^{20,21}$ However, lung disease has not been well investigated in the MCS population and to date, there has been no concerted effort to evaluate the efficacy of PFTs as predictors of mortality in this patient population. Ghotra and colleagues ${ }^{22}$ presented preliminary data suggesting a significant association between DLCO less than $50 \%$ predicted and increased mortality in their patients undergoing MCS at a single center.

In this study, patients with very low PFTs were implanted with ventricular assist devices. A significant percentage of patients underwent redo sternotomy, and a third had additional

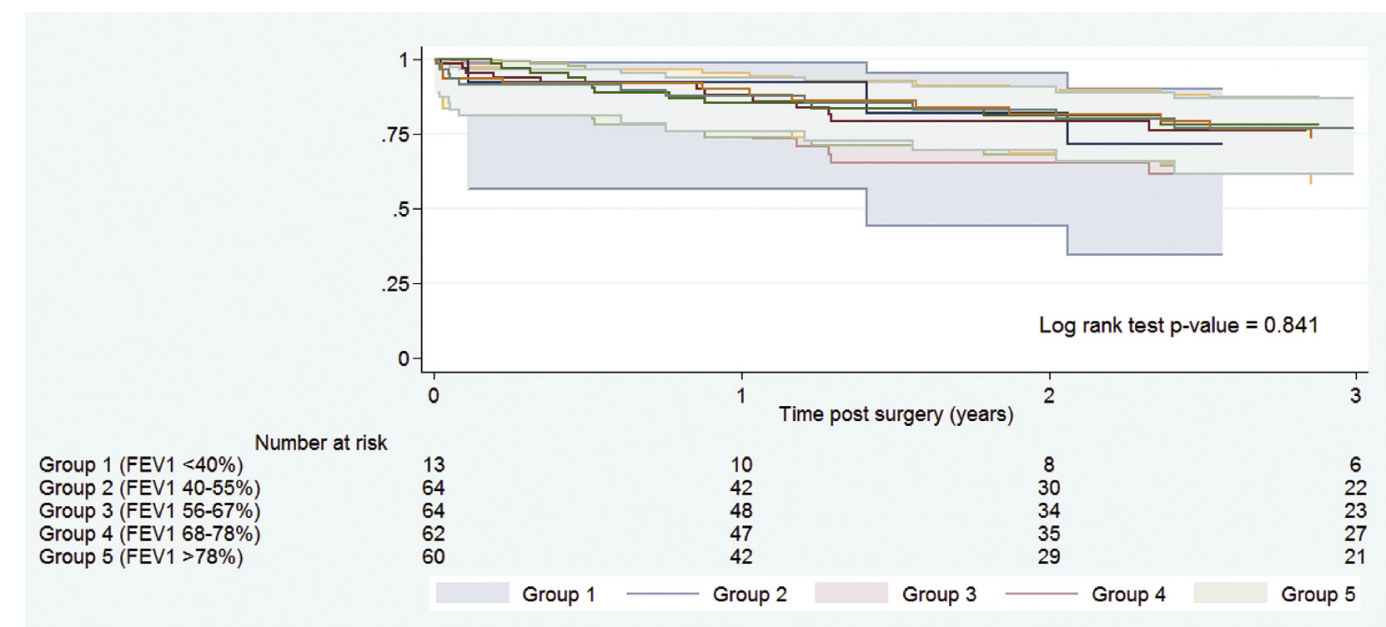

FIGURE 1. Kaplan-Meier survival estimates for patients by $\mathrm{FEV}_{1}$ groups (Group 1: $<40 \%$, Group 2: 40\%-55\%, Group 3: 56\%-67\%, Group 4: $68 \%-78 \%$, Group 5: $>78 \%$ ). $F E V_{1}$, Forced expiratory volume in 1 second. 


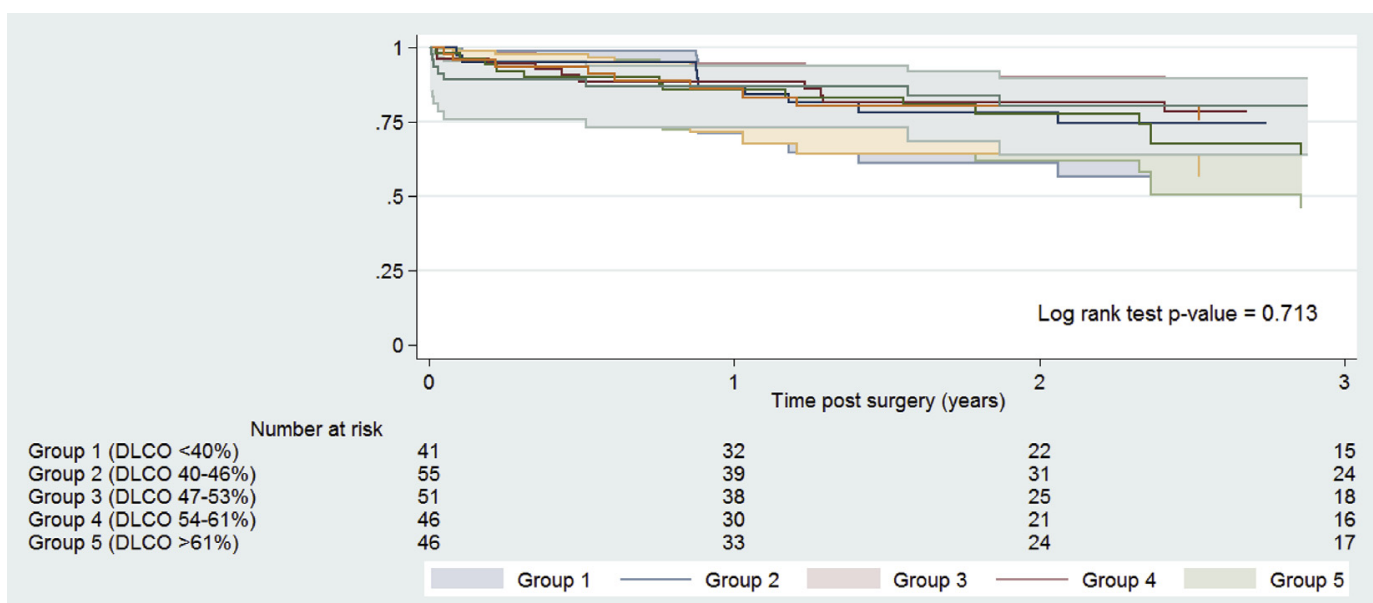

FIGURE 2. Kaplan-Meier survival estimates for patients by DLCO groups (Group 1: $<40 \%$, Group 2: 40\%-46\%, Group 3: 47\%-53\%, Group 4: $54 \%-61 \%$, Group 5: $>61)$. DLCO, Diffusion capacity of the lungs for carbon monoxide.

procedures during device implantation. However, we found no association between either DLCO or $\mathrm{FEV}_{1}$ with mortality. These findings may be anticipated; by modifying patients' heart failure with treatment, the natural history of their PFTs could be altered. For example, it is known that DLCO and $\mathrm{FEV}_{1}$ worsen with heart failure as the heart dilates and left ventricular end-diastolic pressure increases, leading to pulmonary interstitial edema and hydrostatic alveolar injury, ${ }^{23}$ but data exist on the improvement of these tests with treatment of heart failure and particularly after heart transplantation. ${ }^{24}$
Therefore, we would expect that with MCS and particularly subsequent transplant (for those transplant-eligible), the pulmonary morbidity would be improved. This would lead to better outcomes in these patients than in patients who undergo nonheart failure surgery where the expected postoperative improvement in pulmonary function may be more limited.

Review of the patients with the lowest $\mathrm{FEV}_{1}$ values shows that pulmonary optimization such as drainage of pleural effusions and oxygen wean contributed at least partially to

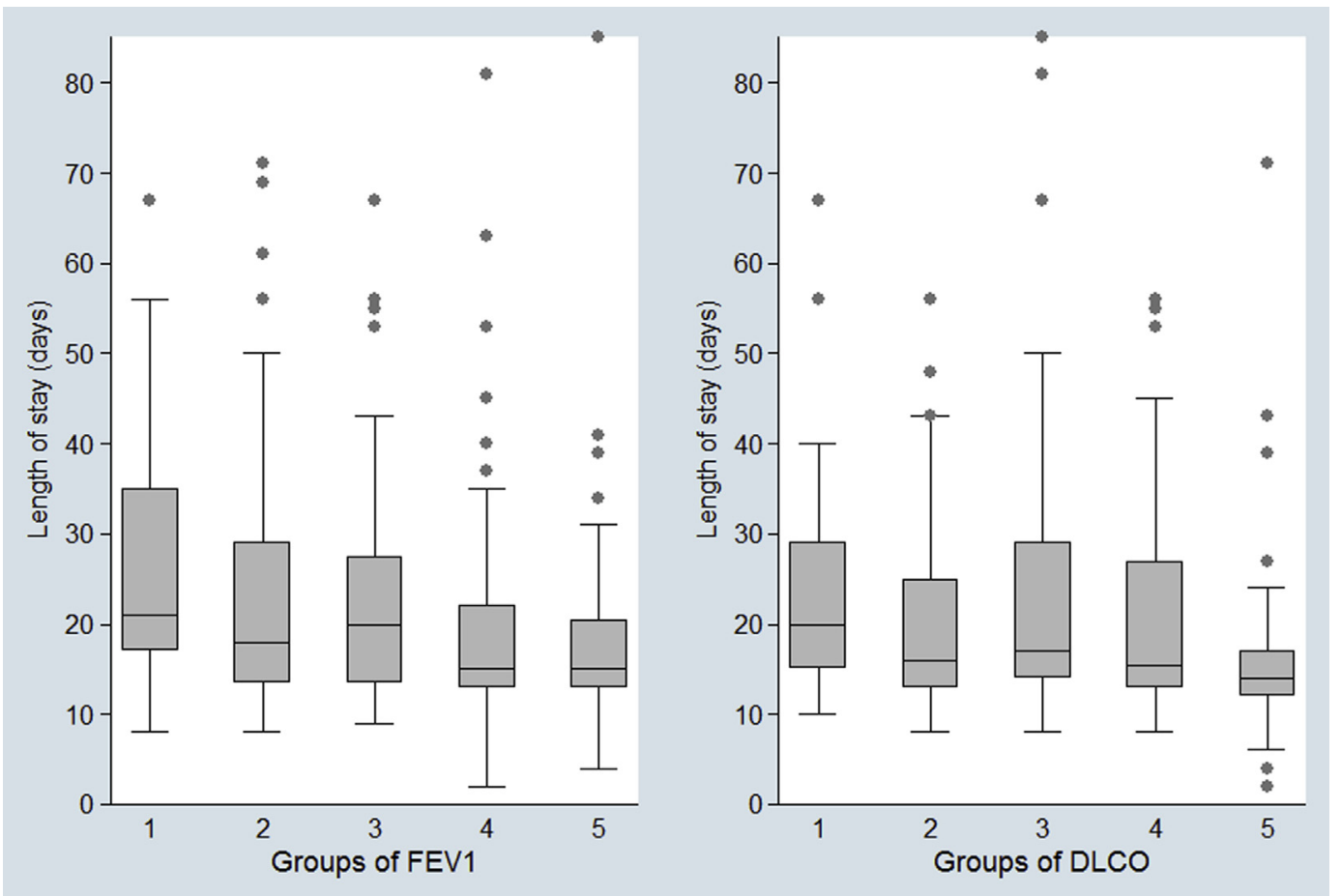

FIGURE 3. Lengths of stay of different patient groups. $\mathrm{FEV}_{1}$ Groups (Group 1: $<40 \%$, Group 2: 40\%-55\%, Group 3: 56\%-67\%, Group 4: 68\%-78\%, Group 5: $>78 \%$ ). DLCO Groups (Group 1: $<40 \%$, Group 2: 40\%-46\%, Group 3: 47\%-53\%, Group 4: 54\%-61\%, Group 5: $>61$ ). FEV , Forced expiratory volume in 1 second; $D L C O$, diffusion capacity of the lungs for carbon monoxide. 


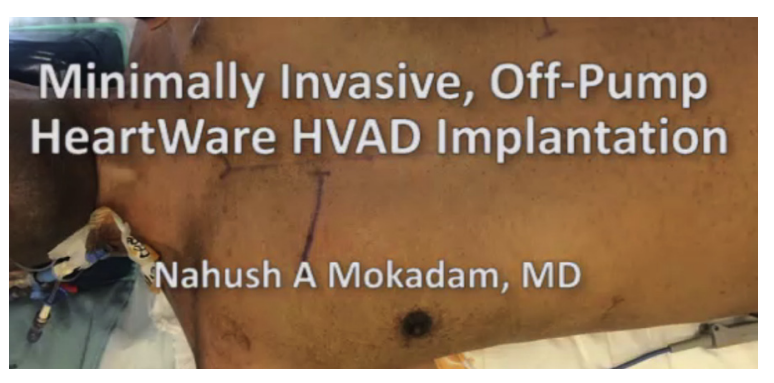

VIDEO 1. Minimally invasive, off-pump implantation of a HeartWare HVAD (HeartWare, Inc., Framingham, Mass). The patient is a 31-year-old man with nonischemic cardiomyopathy and a dilated left ventricle. Right ventricular function was reasonable for isolated LVAD implantation. The ventricular apex was marked with a transthoracic echocardiogram. An 8-cm incision was made in the left sixth interspace, the seventh rib was divided, a softtissue retractor was placed, and a pericardial well created. Simultaneously, a right third interspace incision was made and the rib was divided. The mammary vessels were ligated. A soft-tissue retractor was placed and a pericardial well was created. An umbilical tape was passed between the incisions for later use as a guide for the outflow graft. The apex was elevated into the field by placing a sponge behind the heart. Radial 2-0 braided sutures with pledgets were placed through the sewing cuff and then tied down (note: the anchoring screw should be loosened but not removed at this point). A pacing wire was placed for rapid ventricular pacing (optional). The pump was primed and prepared on the back table. Sizing of the incision was confirmed with the pump, and the patient was heparinized with a goal activated clotting time of $300 \mathrm{sec}-$ onds. A cruciate incision was made in the apex under rapid ventricular pacing. The coring tool was inserted atraumatically (note: once the coring tool is flush with the sewing cuff, it is generally hemostatic). Coring was then completed and the LVAD inserted with the outflow graft unclamped for deairing (note: during this process, approximately $100 \mathrm{~mL}$ of blood can be lost). The umbilical tape was tied to the outflow graft and tunneled to the right thoracotomy incision. The driveline was tunneled out the abdominal wall leaving the velour buried, looped in the pericardium, and then attached to the controller. A side-biting clamp was placed on the aorta, and the outflow graft anastomosis was performed with a 5-0 monofilament suture. A de-airing needle was placed in the outflow graft. The LVAD was then started and slowly increased to nominal speed of $2400 \mathrm{rpm}$. The apex was covered with a Gore-Tex (Gore, Newark, De) pericardial membrane and the right thoracotomy pericardial incision was closed primarily. A paracostal suture was placed over the apex and the wound closed in layers. The right third rib was reapproximated and the wound closed in layers. Transesophageal echocardiography confirmed excellent inflow orientation; a topogram demonstrates the overall lay of the pump. The patient made an excellent recovery and awaits heart transplant. $L V A D$, Left ventricular assist device. Video available at: http://www.jtcvsonline.org/article/S0022-5223(17) 30675-X/fulltext.

increased LOS in one half of the patients with prolonged hospital stays. However, other significant factors like severe right ventricular failure, renal dysfunction, and exercise deconditioning were other etiologies that contributed. Again, there was no observed difference in postoperative pulmonary morbidity as characterized by reintubation rates, ventilator time, tracheostomy rates, and pneumonia. This finding further supports the principle that measured preoperative PFTs may be indicators of cardiac, more so, than pulmonary disease in this patient population.
These findings may help explain the observations in our group analysis, where we found that while generally showing increased ICU LOS with worsening DLCO, patients in the lowest DLCO group showed no significantly longer ICU LOS than those in the normal group, although they did not have increased early mortality. The major contributor to these patients' preoperative performance may be their severe cardiac dysfunction that is then rapidly improved postoperatively, allowing more rapid transit through the ICU.

The economic impact of longer LOS with poor PFTs cannot be ignored. LVAD surgery is expensive, as demonstrated in a Columbia University study, which reported an initial hospitalization cost of $\$ 169,535$ for a 37 -day stay. ${ }^{25}$ Thus, although the overall survival was the same in our analysis, the increase of 10 days in overall hospital LOS for patients with the worst $\mathrm{FEV}_{1}$ values can have a meaningful impact on hospital and personnel resource use. Perhaps future studies can clarify what interventions, if any, when applied to patients with the worst PFT values can decrease the LOS differences observed. Since this study, our practice has evolved in the use of PFTs as part of preoperative evaluation of patients undergoing LVAD implantation. When patients have concerning PFT values, we work collaboratively with our pulmonary medicine colleagues, obtain cross-sectional imaging for evaluation of pulmonary parenchymal disease, determine obvious clinical morbidity such as oxygen dependence, and perform functional tests such as the 6-minute walk test and cardiopulmonary exercise testing as tolerated. The integration of this assessment ultimately guides patient selection with respect to pulmonary comorbidity.

\section{Limitations}

This study was retrospective and nonrandomized and thus limited by the usual confinements of such studies. The data obtained were abstracted from a quality improvement database, which had limited fields of data. Importantly, it is likely that some patients with very low PFTs and other comorbidities were evaluated but not offered MCS during the period under review and thus not analyzed. The small number of patients in the lowest $\mathrm{FEV}_{1}$ group may not be sufficient to demonstrate small survival differences. Patients did not routinely undergo postimplant PFTs, and, therefore, we are unable to evaluate changes in these measures over time. Furthermore, not all patients underwent pulmonary function testing before LVAD implantation.

\section{CONCLUSIONS}

This study finds no association between abnormal PFTs and increased mortality after continuous flow LVAD implantation. Our program performs a multidisciplinary evaluation that takes patient comorbidities into consideration. Our experience suggests that carefully selected patients, including those with PFT abnormalities, can 
undergo MCS with excellent survival. Therefore, PFTs alone should not preclude advanced heart failure therapies to such patients.

\section{Conflict of Interest Statement}

Dr Mahr is a consultant to St Jude, HeartWare, and Abiomed. Dr Mokadam is a consultant to St Jude, HeartWare, and Syncardia Systems Inc. Dr Smith reports a relationship with HeartWare and Transmedics. Drs Pal and Levy report research grants from HeartWare. Dr Dardas reports research support from International Society of Heart Lung Transplant/HeartWare. All other authors have nothing to disclose with regard to commercial support.

We thank Orvalho Augusto for assistance with statistical analysis.

\section{References}

1. Go AS, Mozaffarian D, Roger VL, Benjamin EJ, Berry JD, Borden WB, et al. Heart disease and stroke statistics-2013 update: a report from the American Heart Association. Circulation. 2013;127:e6-245.

2. Yancy CW, Jessup M, Bozkurt B, Butler J, Casey DE, Drazner MH, et al. 2013 ACCF/AHA Guideline for the management of heart failure: a report of the American College of Cardiology Foundation/American Heart Association Task Force on practice guidelines. Circulation. 2013;128:e240-327.

3. Shih T, Paone G, Theurer PF, McDonald D, Shahian DM, Prager RL. The Society of Thoracic Surgeons adult cardiac surgery database version 2.73: more is better. Ann Thorac Surg. 2015;100:516-21.

4. Iversen KK, Kjaergaard J, Akkan D, Kober L, Torp-Pedersen C, Hassager C, et al. The prognostic importance of lung function in patients admitted with heart failure. Eur J Heart Fail. 2010;12:685-91.

5. Olson T, Denzer D, Sinnett W, Wilson T, Johnson B. Prognostic value of resting pulmonary function in heart failure. Clin Med Insights Circ Respir Pulm Med. 2013;7:35-43.

6. de Oliveira EK, da Silva VZM, Turquetto ALR. Relationship of postoperative walk test and lung function with the length of heart surgery hospital stay. Rev Bras Cir Cardiovasc. 2009;24:478-84.

7. Henn MC, Zajarias A, Lindman BR, Greenberg JW, Melby SJ, Quader N, et al. Preoperative pulmonary function tests predict mortality after surgical or transcatheter aortic valve replacement. J Thorac Cardiovasc Surg. 2016;151: 578-86.e2.

8. Zibrak JD, O'Donnell CR, Marton K. Indications for pulmonary function testing. Ann Intern Med. 1990;112:763-71.

9. Hawkins NM, Petrie MC, Jhund PS, Chalmers GW, Dunn FG, McMurray JJV. Heart failure and chronic obstructive pulmonary disease: diagnostic pitfalls and epidemiology. Eur J Heart Fail. 2009;11:130-9.

10. Ivanov A, Yossef J, Tailon J, Worku BM, Gulkarov I, Tortolani AJ, et al. Do pulmonary function tests improve risk stratification before cardiothoracic surgery? J Thorac Cardiovasc Surg. 2016;151:1183-9.e3.

11. Cohen A, Katz M, Katz R, Hauptman E, Schachner A. Chronic obstructive pulmonary disease in patients undergoing coronary artery bypass grafting. J Thorac Cardiovasc Surg. 1995;109:574-81.

12. Bevelaqua F, Garritan S, Haas F, Salazar-Schicchi J, Axen K, Reggiani J-L. Complications after cardiac operations in patients with severe pulmonary impairment. Ann Thorac Surg. 1990;50:602-6.

13. Berry MF, Jeffrey Yang C-F, Hartwig MG, Tong BC, Harpole DH, D'Amico TA, et al. Impact of pulmonary function measurements on long-term survival after lobectomy for stage i non-small cell lung cancer. Ann Thorac Surg. 2015;100:271-6.

14. Kirklin JK, Naftel DC, Pagani FD, Kormos RL, Stevenson LW, Blume ED, et al. Sixth INTERMACS annual report: a 10,000-patient database. J Heart Lung Transplant. 2014;33:555-64.

15. Lietz K, Miller LW. Improved survival of patients with end-stage heart failure listed for heart transplantation. J Am Coll Cardiol. 2007;50:1282-90.

16. Flint KM, Matlock DD, Lindenfeld J, Allen LA. Frailty and the selection of patients for destination therapy left ventricular assist device. Circ Heart Fail. 2012;5:286-93.
17. Demirozu ZT, Hernandez R, Mallidi HR, Singh SK, Radovancevic R, Segura AM, et al. HeartMate II left ventricular assist device implantation in patients with advanced hepatic dysfunction. J Card Surg. 2014;29:419-23.

18. Sargent JE, Dardas TF, Smith JW, Pal JD, Cheng RK, Masri SC, et al Periportal fibrosis without cirrhosis does not affect outcomes after continuous flow ventricular assist device implantation. J Thorac Cardiovasc Surg. 2016; 151:230-5.

19. Sandner SE, Zimpfer D, Zrunek P, Rajek A, Schima H, Dunkler D, et al. Rena function and outcome after continuous flow left ventricular assist device implantation. Ann Thorac Surg. 2009;87:1072-8.

20. Coffin ST, Waguespack DR, Haglund NA, Maltais S, Dwyer JP, Keebler ME Kidney dysfunction and left ventricular assist device support: a comprehensive perioperative review. Cardiorenal Med. 2015;5:48-60.

21. Yoshioka D, Sakaguchi T, Saito S, Miyagawa S, Nishi H, Yoshikawa Y, et al Predictor of Early mortality for severe heart failure patients with left ventricular assist device implantation. Circ J. 2012;76:1631-8.

22. Ghotra AS, Hussain Z, Bhatia N, Perez R, Cheng A, Slaughter MS, et al. Impact of pulmonary function tests on outcomes in patients after left ventricular assist device implantation. J Card Fail. 2015;21:S93.

23. Apostolo A, Giusti G, Gargiulo P, Bussotti M, Agostoni P. Lungs in heart failure. Pulm Med. 2012;2012:1-9.

24. Mettauer B, Lampert E, Charloux A, Zhao QM, Epailly E, Oswald M, et al Lung membrane diffusing capacity, heart failure, and heart transplantation. Am J Cardiol. 1999;83:62-7.

25. Miller LW, Guglin M, Rogers J. Cost of ventricular assist devices: can we afford the progress? Circulation. 2013;127:743-8.

Key Words: heart failure, mechanical circulatory support, heart transplantation, pulmonary function tests

\section{Discussion}

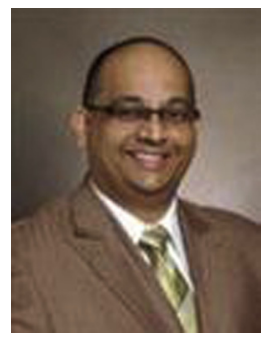

Discussant 1: Dr Sagar Damle

\section{Discussant 2}

\section{Discussant 3: Dr Dan Miller}

Moderator: Dr Craig Sussman

\section{Presenter: Dr Edo Bedzra}

Dr Craig Sussman. Our next speaker is from the University of Washington, presenting "Pulmonary Function Tests Do Not Predict Mortality in Patients Undergoing Continuous Flow LVAD Implantation," Dr Edo Bedzra.

Dr Edo Bedzra. Good morning. I thank the Western Thoracic Surgical Association for the privilege of presenting our research into the prognostic efficacy of PFTs in patients undergoing continuous-flow LVAD implantation. These are our disclosures. PFTs are known to portend an increased risk of mortality in general cardiac surgery, as shown by this evaluation of the Society of Thoracic Surgeons risk calculator. Specifically, patients with $\mathrm{FEV}_{1}$ less than $50 \%$ had 1.77 times the operative mortality of patients with $\mathrm{FEV}_{1}$ greater than $75 \%$. The presence of pulmonary disease also is known to increase risk of mortality in heart failure. In this 2010 analysis, 532 patients with medically managed heart failure were evaluated. In the multivariable analysis, each $10 \%$ decrease in $\mathrm{FEV}_{1}$ was associated with a $14 \%$ increase in risk of mortality. Now, this may be 
because of the known consequences of heart failure such as a restrictive effect of cardiomegaly and the adverse interstitial and hydrostatic alveolar injury caused by an elevated left ventricle and diastolic pressure. However, it also is known that treatment of heart failure leads to improvement in observed PFTs.

Keeping this in mind, we set out to examine our experience in mechanical circulatory support surgery. Our aim was to explore the effects different preoperative PFTs had on postoperative outcomes after continuous-flow LVAD implantation. We obtained institutional review board approval from the University of Washington, Human Subjects Division, to retrospectively review our mechanical circulatory support quality improvement database. A total of 310 sequential patients who underwent LVAD implantations for all indications between 2005 and 2015 were evaluated. Patients with no preoperative testing were analyzed separately. A total of 263 patients underwent spirometry, and a subset of these also underwent DLCO testing. We divided our patients into 5 groups. We arbitrarily chose the sickest cohort to represent patients with percent predicted values of less than $40 \%$. The rest of the patients were then evenly distributed over the remaining 4 groups to allow for statistical comparison. Kaplan-Meier survival analysis was used for evaluation of overall survival.

Overall survival analysis was conducted using the Kaplan-Meier method, cumulative mortality with the Cox proportional hazard model and Length of stay using negative binomial regressions. Corrections were made for age, sex, INTERMACS profile, serum creatinine, reoperative status, and cardiopulmonary bypass time in the multivariable model. For the sake of simplicity, we will focus our discussion on the $\mathrm{FEV}_{1}$ analysis, recognizing that the DLCO analysis was nearly identical. The average patient was a 54-year-old man who presented to implantation stable on inotropes. There was a 4:1 ratio of Heartmate II to HVAD implantations, with nearly half of this as bridged to transplantation. A total of $17.3 \%$ of patients were supported with an intra-aortic balloon pump at implantation. The average patient presented with some element of renal dysfunction and depressed left ventricular end diastolic pressure ejection fraction of $19.7 \%$, resulting in an increased left ventricle and diastolic pressure, manifested by the pulmonary capillary wedge pressure of 22.2. A total of $19.8 \%$ of patients underwent a previous sternotomy before LVAD implantation; $31.2 \%$ of patients had an additional procedure, including the $25 \%$ who underwent tricuspid valve repair; and $2.7 \%$ of patients required a right ventricular device implantation at the time of surgery.

The average cardiopulmonary bypass time was 19.8 minutes. Kaplan-Meier survival analysis of patients who underwent $\mathrm{FEV}_{1}$ testing showed no difference in survival across the 5 groups. The overall survival at 3 years for this group was $78 \%$. Similarly, in the DLCO analysis, no difference in mortality was found between the 5 groups. The $\log$ rank $P=.713$ for this group, and the overall 3year survival was 76.2. Analysis of the entire 310 patient cohort revealed a survival at 3 years of $75.5 \%$. In the univariable and multivariable analysis, neither decreased DLCO nor $\mathrm{FEV}_{1}$ was associated with an increased risk of mortality; however, increasingly normal tests were associated with significantly shorter LOS. It is worth noting here that each $10 \%$ increase in $\mathrm{FEV}_{1}$ or DLCO was associated with a $7 \%$ decrease in the hospital LOS. I apologize that this slide is busy. Please permit me then to highlight the significant findings in our multivariable analysis. Age greater than 60 years, female sex, and increased cardiopulmonary bypass time were associated with significantly increased risk of mortality.

Younger patients had shorter ICU LOS; however, this did not translate into shorter overall hospital LOS. Female patients with increased cardiopulmonary bypass time had significantly longer LOS. A total of 47 patients had no $\mathrm{FEV}_{1}$ testing preoperatively, and 71 patients had no DLCO testing. These patients were, on average, 4 years younger than patients who underwent testing. They were more likely to present with cardiac and renal dysfunction on inotropic support and more likely to be supported with an intra-aortic balloon pump. In our program, the policy is to obtain preoperative testing on all patients. Therefore, the absence of PFTs indicates an inability to obtain them prior to implant further confirming a sicker patient cohort. However, when these patients were included in the sickest group, patients with $\mathrm{FEV}_{1}$ less than $40 \%$, there was no change in the significance of observed results. LOS was prolonged, as previously observed. This study is nonrandomized and retrospective and thus limited by the usual confinement of such studies. Data were abstracted from an administrative database but limited field.

Importantly, it is likely that some patients with very low $\mathrm{FEV}_{1}$ and other comorbidities were evaluated but not offered MCS. As well, not all patients underwent preoperative testing. It is also important to note that we did not evaluate pulmonary morbidity such as ventilator time and pneumonia, because these data were not available. However, our sensitivity analysis has shown robust results, and therefore we think our results are generalizable to patients undergoing LVAD implantation. In summary, in our population, abnormal PFTs did not seem to confer an increased risk of mortality; however, PFTs may be useful predictors of postoperative LOS. In our experience, patients including those with abnormal PFTs can undergo mechanical circulatory support with acceptable outcomes, including acceptable mortality. Therefore, PFTs alone should not preclude the offer of advanced heart failure therapy to carefully selected patients. I would like to thank Orvalho Augusto for his help in the statistical analysis, and I'd personally 
like to acknowledge Dr Mokadam for his mentorship through this process. Thank you and now onto your questions.

Dr Sussman. The discussion will be opened up by Dr Sagar Damle.

Dr Sagar Damle. First, I'd like to thank the association for giving me the opportunity to discuss this paper, and I'd like to congratulate the authors on a well-written, provocative manuscript and a well-prepared presentation. In the interest of time, I won't rehash all of your findings. I will comment that after reading the manuscript, I had several questions. Let me start with my first question, and it relates to your separation into quintiles. In routine practice, we generally accept $\mathrm{FEV}_{1}$ and DLCO values greater than $40 \%$ as acceptable for really any kind of cardiac surgical procedure. Did you perform a comparison of the "Quintile 1 less than 40\%" versus all others and would you suspect that that might change your significance in terms of differences?

Dr Bedzra. Thank you for the question. We did not actually examine quintile 1 less than $40 \%$ compared with the rest of the groups. Now, having said that, the univariate and multivariable analysis was performed in a linear manner, and this did not show any significant differences, so I do not expect that there would be any difference if we had examined it that way.

Dr Damle. PFTs and specifically FEV F $_{1}$ and DLCO can be somewhat crude measures and incomplete measures of a patient's true pulmonary frailty or pulmonary risk. In addition, as you mentioned both in your talk and in the manuscript, both of those values can be greatly affected by a patient's volume status and degree of heart failure. You mentioned that the average wedge pressure was 22 in this group. So, my first question related to this topic is when were the PFTs measured in relationship to when VAD was implanted?

Dr Bedzra. Thank you. Again, it's our policy that we obtain routine preoperative testing for patients as recent as less than 1 year before implantation.

Dr Damle. The reason why I bring that up is that, you know, you had a significant percentage of the patients had balloon pumps before implant, and even in the group that did not have PFTs, there was a greater percentage of patients who had balloon pumps, clearly demonstrating a sicker population. PFTs that are measured a year before implant may or may not be relevant in terms of what their true value is. The second question then is did you have an opportunity to reexamine these patients after LVAD implant to see whether their PFTs improved, especially in the quintile one patients?

Dr Bedzra. That's an excellent question. We do not routinely obtain postoperative PFTs in these patients. Some have been obtained, however, we have not been able to examine that data yet.
Dr Damle. I'm sure your group, just like ours, gets a full set of PFTs with arterial blood gases. Did you, by any chance, measure any of the other markers from your PFT examinations, such as room air $\mathrm{O}_{2}$ level, room air $\mathrm{CO}_{2}$ level, or their degree of pulmonary hypertension, specifically in the quintile 1 group versus the others?

Dr Bedzra. We did not. However, one could look at the left ventricular end diastolic pressure as well as the right ventricular pressures as proxy for pulmonary hypertension. We do have hemodynamic data reflecting this and that's provided in our manuscript as well. These were mildly elevated, as suspected in this population.

Dr Damle. PFTs are a common preoperative test. The vast majority is performed on pretty ill patients with an LVAD. In your series, $85 \%$ of these patients have preoperative PFTs, but as we all know, PFTs are really just one of the plethora of factors that are used in the decision process for LVAD implantation. I'd like to emphasize one key limitation, which you also mentioned in your paper. That is, we don't know anything about the patients who are not offered LVADs. Specifically, we don't know what percentage of those patients were denied LVAD specifically on the basis of poor pulmonary function. I suspect your group of the low PFTs, that quintile 1 group, really represents a very select group of patients. Can you comment on the specific interquartile differences with regard to other comorbidities, not just their age or their INTERMACS score, but what were the other differences between the quartiles recognized that they may not be statistically significant, I'm sure you were able to identify trends between the quartiles. Can you comment on maybe some of the differences between the low $\mathrm{FEV}_{1}$ patients versus the others?

Dr Bedzra. Thank you. That's an excellent question. We do have data on the demographic profile of these patients in the different quintiles. As you alluded to, there weren't any significant differences in between these. Looking at the data, the most significant difference existed in the patients supported with intra-aortic balloon pumps, however, even this varied from about $19 \%$ supported to about $25 \%$, which was not very significant clinically. The only other significant difference was in age, and there was about a 5-year difference across the 5 groups. This was not statistically significant.

Dr Damle. Right and again, I agree with you. It's not statistically significant but the numbers were relatively small. Sometimes it's hard to reach statistical significance. It is something that I think you should include in your manuscript to let the reader decide how important that is to know.

Dr Bedzra. We will do that. Thank you.

Dr Damle. Ultimately, I agree with your conclusion that an isolated test such as an $\mathrm{FEV}_{1}$ or a DLCO should not in and by itself be a decision maker for LVAD implant. I believe what your paper really highlights is that when 
appropriately selected patients undergo VAD implantation, at an experienced center such as yours, even patients with seemingly poor pulmonary function can have excellent results. I congratulate you on your work.

Dr Bedzra. Thank you.

Discussant 2. I'd like to ask a question. We know Dr Mokudan will dress a cadaver so that he can operate on them, so my question is when do you not operate on a patient? I mean, if somebody in a wheelchair comes in on 6 liters of oxygen, they have a DLCO of 25 , are you still operating on these patients?

Dr Bedzra. That is an excellent question. Thank you. As Dr Damle alluded to, I think the crux of this paper is that one test does not determine the performance of the patient postoperatively.

Discussant 2. So why do you do the test? You said it's your protocol that you do preoperative PFTs, so why are you getting the test?

Dr Bedzra. Yes, so we use the test in conjunction with other measures of pulmonary morbidity, such as the presentation of the patient. Is he in a wheelchair, is he using oxygen, what are the computed tomography scan findings, and whether there is any morbidity or ambiguity. We do evaluate these patients using a cardiopulmonary exercise test to look at their cardiopulmonary exercise conditioning.

Discussant 2. But they have heart failure. They're all going to have a low cardiopulmonary exercise test score. If you're doing a VAD on somebody with a $\mathrm{VO}_{2}$ of 18 , then you probably shouldn't be doing it. How low is low? We want a number. The people in this audience want a number. When will the University of Washington not do an LVAD on a patient?
Dr Bedzra. Yeah, that's an excellent question. I can tell you that ... I can tell you that in our database, our FEV values go as low as $23 \%$; however, as has been previously mentioned, we did not evaluate patients with numbers less than this and, in fact, we have had patients with lower numbers that we had to turn down because of LVAD comorbidities, so I cannot give you an absolute number, especially since we didn't do statistical analysis looking at inflection points on this database, but I can assure you that we take all the comorbidities and tests into consideration when deciding on whom to operate.

Discussant 2. Thank you.

Dr Bedzra. Thank you.

Dr Sussman. Dan Miller.

Dr Dan Miller. Great presentation. When you include PFTs for evaluation, I think it's very important especially in these patients, you've got to look at their smoking status, their pack years, and also their oxygen supplementation before. If they're on 1 liter, if they're on 6 liters, you know, they're in a wheelchair, you know, whatever, but you've got to include $\mathrm{O}_{2}$ supplementation and smoking in this to get a better idea because there are going to be some patients, 120 pack-year smokers, on 6 to 8 liters. A patient shouldn't be done, but you have to clarify that group. You have that information, you just need to pull that out.

Dr Bedzra. Thank you. The database we have currently does not capture that; however, a reasonable proxy for that is the $\mathrm{FEV}_{1}$ to $\mathrm{FVC}$ ratio or the FVF $25 \%$ to $70 \%$. Although that data is not presented here, we have analyzed that and the findings are entirely similar to what we've presented.

Dr Sussman. Thank you.

Readers who found these articles interesting may also like to read the following papers found in recent and future issues of our sister publications, Seminars in Thoracic and Cardiovascular Surgery and Operative Techniques in Thoracic and Cardiovascular Surgery!

Acquired: Mechanical Circulatory Support

ORIGINAL SUBMISSION: Central Cannulation as a Viable Alternative to Peripheral Cannulation in Extracorporeal Membrane Oxygenation David N. Ranney. Semin Thoracic Surg 2017: 188-195.

Editorial Commentary: Primmum Nil Nocere, Second be Cautious and Third Try to Use the Right Extracorporeal Membrane Oxygenator Modality D Berdajs. Semin Thoracic Surg 2017: 196-197.

ORIGINAL SUBMISSION: Minimally Invasive Implantation: The Procedure of Choice! Jan D. Schmitto. Oper Tech Thorac Cardiovasc 2016: 60-73. 
TABLE E1. Correlation of postoperative outcomes with pulmonary function test categories

\begin{tabular}{|c|c|c|c|c|c|c|}
\hline Characteristic & 1 & 2 & 3 & 4 & 5 & $P$ value \\
\hline \multicolumn{7}{|l|}{$\mathrm{FEV}_{1}$ group } \\
\hline $\mathrm{n}$ & 13 & 64 & 64 & 62 & 60 & \\
\hline \multicolumn{7}{|l|}{ Mortality } \\
\hline Unadjusted, HR (95\% CI) & $1.11(0.3-4.0)$ & $1.03(0.5-2.4)$ & $0.95(0.4-2.2)$ & $1.05(0.5-2.4)$ & 1 & .999 \\
\hline Adjusted, HR (95\% CI) & $0.83(0.2-3.2)$ & $0.75(0.3-1.7)$ & $0.71(0.3-1.7)$ & $0.90(0.4-2.1)$ & 1 & .934 \\
\hline Spline analysis, HR $(95 \% \mathrm{CI})$ & $1.02(0.8-1.3)$ & $0.96(0.9-1.0)$ & $1.05(1.0-1.1)$ & $1.01(0.96-1.05)$ & 1 & .713 \\
\hline Hospital length of stay, $d$, mean (SD) & $28.2(17.4)$ & $23.7(15.2)$ & $22.6(12.6)$ & $21.2(14.3)$ & $18.0(11.8)$ & \\
\hline Unadjusted ratio $(95 \% \mathrm{CI})$ & $1.55(1.1-2.1)$ & $1.32(1.1-1.6)$ & $1.25(1.0-1.5)$ & $1.10(1.0-1.5)$ & 1 & .012 \\
\hline Adjusted ratio $(95 \% \mathrm{CI})$ & $1.43(1.0-2.0)$ & $1.27(1.1-1.5)$ & $1.22(1.0-1.5)$ & $1.07(0.9-1.3)$ & 1 & .04 \\
\hline ICU length of stay, mean (SD) & $8.5(4.1)$ & $7.5(6.7)$ & $8.7(9.8)$ & 8.7 (11.4) & $7.1(8.1)$ & \\
\hline Unadjusted ratio $(95 \% \mathrm{CI})$ & $1.18(0.7-1.9)$ & $1.09(0.8-1.4)$ & $1.20(0.9-1.6)$ & $1.15(0.9-1.5)$ & 1 & .719 \\
\hline Adjusted ratio $(95 \% \mathrm{CI})$ & $1.08(0.7-1.7)$ & $1.05(0.8-1.4)$ & $1.13(0.9-1.5)$ & $1.03(0.8-1.4)$ & 1 & .915 \\
\hline \multicolumn{7}{|l|}{ DLCO group } \\
\hline $\mathrm{n}$ & 41 & 55 & 55 & 48 & 40 & \\
\hline \multicolumn{7}{|l|}{ Mortality } \\
\hline Unadjusted, HR (95\% CI) & $1.20(0.5-3.1)$ & $1.00(0.4-2.6)$ & $1.55(0.6-3.7)$ & $1.69(0.6-4.4)$ & 1 & .837 \\
\hline Adjusted, HR (95\% CI) & $0.95(0.4-2.6)$ & $0.83(0.3-2.2)$ & $1.46(0.6-3.6)$ & $1.13(0.4-3.0)$ & 1 & .754 \\
\hline Spline analysis, HR $(95 \% \mathrm{CI})$ & $0.90(0.8-1.0)$ & $1.2(1.0-1.4)$ & $0.89(0.7-1.1)$ & $1.0(0.9-1.1)$ & 1 & .395 \\
\hline Hospital length of stay, $d$, mean (SD) & $23.9(13.1)$ & $19.4(10.0)$ & $24.4(16.9)$ & $21.6(13.3)$ & $17.0(11.0)$ & \\
\hline Unadjusted ratio $(95 \% \mathrm{CI})$ & $1.41(1.1-1.8)$ & $1.14(0.9-1.4)$ & $1.44(1.2-1.8)$ & $1.27(1.0-1.6)$ & 1 & .005 \\
\hline Adjusted ratio $(95 \% \mathrm{CI})$ & $1.44(1.2-1.8)$ & $1.16(0.9-1.4)$ & $1.46(1.2-1.8)$ & $1.33(1.1-1.6)$ & 1 & $<.001$ \\
\hline ICU length of stay, mean (SD) & $6.8(3.5)$ & $6.8(4.2)$ & $11.1(15.7)$ & $8.5(8.3)$ & $5.8(4.8)$ & \\
\hline Unadjusted ratio $(95 \% \mathrm{CI})$ & $1.16(0.8-1.6)$ & $1.17(0.9-1.6)$ & $1.89(1.4-2.5)$ & $1.46(1.1-2.0)$ & 1 & $<.001$ \\
\hline Adjusted ratio $(95 \% \mathrm{CI})$ & $1.19(0.9-1.6)$ & $1.16(0.9-1.5)$ & $1.78(1.3-2.4)$ & $1.46(1.1-2.0)$ & 1 & $<.001$ \\
\hline
\end{tabular}
carbon monoxide. 